7. Philip R, Berger AC, McManus NH, et al. Abnormalities of the in vitro cellular and humonal responses to tetanus and influenza antigens with concomitant numerical alterations in lymphocyte subsets in Down syndrome (trisomy 21). J Immtmol. 1986;136:1661- 1667.

8. Hawkes RA, Boughton CR, Schroeter DR. The antibody response of institutionalized Down's syndrome patients to seven microbial antigens. Clin Exp Immunol. 1978;31:298-304.

9. Kroon FP, van Tol MJ, Jol-van der Zijde CM, van Furth $R$, et al Immunoglobulin $\mathrm{G}$ (IgG) subclass distribution and $\mathrm{IgCl}$ avidity of antibodies in human immunodeficiency virus-infected individuals after revaccination with tetanus toxoid. Clin Diagn Lab Immtnol. 1999;6:352--355.

10. Davis CM, Kancherla VS, Reddy A, et al. Development of specific T-cell responses to Candida and tetanus antigens in partial DiGeorge syndrome. J Allergy Clin Imminol. 2008;122:1194-1199.

11. Barbi $M$, Biffi $M R$, Binda $S$, et al. Immunization in children with HIV seropositivity at birth: antibody response to polio vaccine and tetanus toxoid. AIDS. 1992;6:1465-1469.

12. Schejbel L, Marquart H, Andersen V, et al. Deficiency of somatic hypermulation of immunoglobulin $G$ transcripts is a better predictor of severe respiratory tract infections than lack of memory $B$ cells in common variable immunodeficiency. J Clin Immmol. 2005;25:392-403.

13. Andersen P, Permin H, Andersen V, et al. Deficiency of somatic hypermutation of the antibody light chain is associated with increased frequency of severe respiratory tract infection in common variable immunodeficiency. Blood. 2005;105:511-517.

\section{NIJMEGEN BREAKAGE SYNDROME COMPLICATED WITH PRIMARY CUTANEOUS TUBERCULOSIS}

\section{Melinda Erdös, MD, PhD,* Beáta Tóth, MSc,* Imre Veres, MD, Mária Kiss, PhD, tívi Remenyik, MD, PhD, $\dagger$ and László Maródi, MD, PhD*}

Abstract: Nijmegen breakage syndrome (NBS) is a rare autosomal recessive chromosomal instability syndrome characterized by severe immunodeficiency, growth retardation, microcephaly, a distinct facial appearance, and a high predisposition to lymphoid malignancy. We report a 7-year-old white girl with NBS associated with cutaneous tuberculosis. The patient presented with multiple red-brown, centrally scaring plaques on the leg and had neither pulmonary nor systemic manifestation of tuberculosis. Polymerase chain reaction testing using Mycobacterium genus- and Mycobacterium tuberculosis species-specific primers confirmed the clinical diagnosis of cutaneous tuberculosis. This is the first report describing the simultaneous presentation of NBS and cutaneous tuberculosis.

Key Words: Nijmegen breakage syndrome, cutaneous tuberculosis

Accepted for publication September 2, 2010.

From the *Department of Infectious and Pediatric Inmunology, Medical and Health Science Center, University of Debrecen, Debrecen, Hungary; †Department of Dermatology, Medical and Health Science Center, University of Debrecen, Debrecen, Hungary; and $\$$ Department of Dermatology and Allergology, Albert Szent-Györgyi Clinical Center, University of Szeged, Hungary.

Supported by grants from the Hungarian Research Fund (OTKA PD 72445) (to M.E.), and the TÁMOP 4.2.1./B-09/1/KONV-2010-0007 project implemented through the New Hungary Development Plan and co-financed by the European Social Fund.

Address for correspondence: László Maródi, MD, PhD, Department of Infectious and Pediatric Immutology, Medical and Health Science Center, University of Debrecen, Nagyerdei krt. 98, H-4032 Debrecen, Hungary. E-mail: Imarodi@dote.hu.

Supplemental digital content is available for this article. Direct URI citations appear in the printed text and are provided in the HTML and PDF versions of this article on the journal's Web site (www.pidj.com). DOI: $10.1097 / \mathrm{LNF}, 0 \mathrm{~b} 013 \mathrm{e} 3181$ faa941

$\mathrm{N}$ ijmegen breakage syndrome (NBS) is a rare, autosomal recessive DNA-repair disorder characterized by severe immunodeficiency, progressive microcephaly, characteristic face, growth retardation, spontaneous chromosomal instability, and a peculiar predisposition to cancer development." The syndrome is caused by mutations in the NBSI gene located on chromosome $8 q 21$, which encodes for nibrin, a DNA double strand break repair protein. ${ }^{2,3}$ The inmune deficiency in affected individuals is profound and highly variable, with a tendency to progress with time. ${ }^{4}$ In particular, defective antibody response to common pathogens and low concentrations of serum immunoglobulin isotypes and IgG subclasses are common. ${ }^{4}$ Cellular immunity is also impaired and manifested in reduced $\mathrm{T}$-lymphocyte proliferation and lymphopenia. The number of $\mathrm{CD}^{+}$and $\mathrm{CD} 4^{-t} \mathrm{~T}$ cells are usually decreased, whereas $\mathrm{CD} 8^{+}$cell depletion is rarely seen. Infectious complications mostly affect the respiratory tract and are caused by community-acquired rather than opportunistic pathogens.

Cutaneous tuberculosis, a very rare manifestation of mycobacterial infections has recently been reported from areas with a high incidence of HIV infection and multidrug-resistant pulmonary tuberculosis. Lupus vulgaris is a characteristic clinical form of cutaneous tuberculosis which typically occurs through hematogenous, lymphatic, or contiguous spread from underlying tuberculosis, also after primary inoculation. ${ }^{5,6}$ It may also be acquired exogenously following secondary inoculation, which is a rare complication of $\mathrm{BCG}$ vaccination. ${ }^{7}$ We present here a unique association of NBS with lupus vulgaris in a 7-year-old girl with neither pulmonary nor systemic manifestations of tuberculosis.

\section{METHODS}

Measurement of serum isotypes and lymphocyte surface markers were performed by routine immunochemical and flow cytometry assays. EDTA blood from the patients and family members was obtained and genomic DNA was isolated by using GenElute Blood Genonic DNA kit (Sigma-Aldrich GmbH, Budapest). Polymerase chain reaction was performed by using 1 primer pair to selectively amplify products of the hot spot region of NBS1 gene in exon 6. Primer sequences are available on request. Amplified segments were purified using a MICROCON YM-100 Centrifugal Filter Devices (Millipore Co, Bedford, MA). Mutational analysis was performed using the BigDye Terminator Cycle sequencing kit (Applied Biosystems, Foster City, CA) and an ABI PRISM 3130 Genetic Analyzer (Applied Biosystems, Foster City, CA).

DNA was isolated from sections of the formalin-fixed paraffin-embedded skin biopsy samples. Mycobacterium DNA was detected by polymerase chain reaction, using Mycobacterium genus- and Mycobacterium tuberculosis species-specific primers. ${ }^{8}$ To demonstrate the presence of suitable DNA, a 268 bp segment of the human $\beta$-globin gene was also amplified.

All studies were approved by the institutional review board of the Medical and Health Science Center of the University of Debrecen. Informed consent was obtained from the parents.

\section{CASE REPORT}

This 7-year-old girl was admitted to our Department for immunologic investigation because of microcephaly, mild psychomotor retardation, and chronic multiple leg scars. She was the fourth child of a nonconsanguineous Hungarian family. The pregnancy was uncomplicated and the child was delivered at term with a birth weight of $3050 \mathrm{~g}$; length, $48 \mathrm{~cm}$; and head circumference, $31.5 \mathrm{~cm}$ (<third percentile). She had received $B C G$ vaccination on the third day of life without complication and with no history of revaccination later. The patient received medical attention because of microcephaly, failure to thrive, and dysmorphic facial features (Fig., A and B, Supplemental Digital Content 1, http://links.lww.com/INF/A607). At 5 years of age, brain magnetic resonance imaging revealed occipital hypoplasia with dilatation of the occipital horns of ventricle. She was 
hospitalized for Campylobacter enterocolitis at the age of 5 , and for bacterial pneumonia at the age of 7 . At age 6 , she presented with painless, slowly, progressively expanding, reddish, discoid plaques on both legs (Fig., E and F, Supplemental Digital Content 1, http://links.lww.com/INF/A607)

On admission, her height was $97 \mathrm{~cm}$; weight, $15 \mathrm{~kg}$; and head circumference, $48 \mathrm{~cm}$, all below the third percentile. She had a "bird-like" face characterized by a prominent midface and large ears, with a receding forehead and mandible, long philtrum, and micrognathia (Fig., A and B, Supplemental Digital Content 1, http://links.lww.com/INF/A607). She was fully cooperative and communicated adequately despite of striking retardation of physical growth and severe microcephaly. Café au lait spots and hypopigmented areas were noticed all over her body. Erythematous, indurated, scaly plaques on the right leg with areas of scarring was observed (Fig., E and F, Supplemental Digital Content 1, http://links.lww.com/INF/A607). The lesions were not painful on palpation.

\section{RESULTS}

Histopathologic examination revealed lupus vulgaris with well-developed noncaseating epithelioid granulomas, with inchoate central necrosis and some Langhans-type giant cells (Fig., C and D, Supplemental Digital Content 1, http://links.lww.com/INF/A607). No mycobacteria were identified in tissue by the Ziehl-Neelsen stain.

Molecular analysis of DNA extracted from paraffin-embedded skin specimen was positive for the $M$. tuberculosis IS6110 insertion sequence. Chest radiograph and abdominal sonography were normal. There was no history of tuberculosis and exposure to patients with tuberculosis. Screening for active tuberculosis in the family was negative.

Laboratory tests showed decreased concentrations of IgG $(0.51 \mathrm{~g} / \mathrm{L})$ and $\operatorname{IgA}$ (undetectable) and normal $\operatorname{IgM}(1.14 \mathrm{~g} / \mathrm{L})$. Flow cytometry analysis of peripheral blood mononuclear cells disclosed decreased number of $\mathrm{CD} 19^{+}$cells $(4 \% ; 0.06 \mathrm{G} / \mathrm{L})$ and $\mathrm{CD}^{+}$cells $(24 \% ; 0.25 \mathrm{G} / \mathrm{L})$, and decreased $\mathrm{CD} 4^{+} / \mathrm{CD} 8^{+}$ratio $(0.55)$. The diagnosis of NBS was confirmed by mutation analysis of NBSI which revealed a c.657del5bp deletion mutation in exon 6 in both alleles, predicting a p.K219fs X234 change in the nibrin protein. Her 16-year-old sister was also diagnosed with NBS. Treatment was commenced with $400 \mathrm{mg} / \mathrm{kg}$ intravenous immunoglobulin infusions every 3 weeks. In addition, the patient was daily given rifampicin $(150 \mathrm{mg})$, isoniazid $(150 \mathrm{mg})$, and ethambutol (200 mg). A favorable outcome of the skin disease was observed, suggesting the beneficial effect of antimycobacterial therapy.

\section{DISCUSSION}

Cutaneous manifestations of tuberculosis are seen in less than $0.5 \%$ of cases. ${ }^{9}$ On the basis of data available from the ESID Registry, association of NBS with lupus vulgaris has not been reported before. Lupus vulgaris is a progressive and common form of cutaneous tuberculosis and usually results from dissemination from pulmonary tuberculosis. It follows a chronic course and without trentment may slowly extend with time. Lupus vulgaris is generally under-diagnosed because of its rarity and diverse clinical manifestations, and lack of awareness of the disease. Disseminated mycobacterium infection in a patient with NBS was reported by Resnick et al. ${ }^{10}$ This patient died at the age of 10 and had no skin manifestations.

NBS patients have defective humoral and cellular inmunity which predispose them to infections. The impaired cellular immunity may play a role in the predisposition to infections by intracellular pathogens including mycobacteria. However, association of this pri- mary immunodeficiency with tuberculosis is surprisingly rare. The case presented in this report is unique, because cutaneous tuberculosis is typically seen in patients with pulmonary tuberculosis. Cutaneous tuberculosis is extremely rare in patients having neither pulmonary nor systemic manifestation of tuberculosis. Our case is also notable because she developed lupus vulgaris, the well-organized form of the pathologic lesions seen in cutaneous tuberculosis. The clinical and pathologic lesions seen in cutaneous tuberculosis vary from scrofirloderma to lupus vulgaris. In scrofuloderma occurring mostly in patients with inmmunodeficiencies, histopathological examinations usually show a large number of mycobacteria in the lesions with a small to moderate number of lymphocytes in the granuloma. In contrast, lupus vulgaris is often seen in immunocompetent patients. In lupus vulgaris, lesional tuberculous bacilli are usually absent or scant, and cultures are often negative. Finally, our child had a favorable response to combined antituberculous therapy despite severe immunodeficiency.

Inborn errors of immunity including interferon $-\gamma$ receptor $\alpha$ and $\beta$ chain deficiencies, signal transducer and activator of transcription 1 deficiency, interleukin (IL)-12 p40 deficiency, IL-12 receptor $\beta 1$ chain deficiency, and nuclear factor- $\kappa B$ essential modulator deficiency have been proposed to predispose patients to infections with various mycobacterial species. ${ }^{11-14}$ Intriguingly, IL-12 $\beta 1$ receptor deficiency has been shown to associate mostly with $M$. tuberculosis infections but not with invasive BCG or environmental mycobacterial disease. The occurrence of $M$. tuberculosis infection in our patient should prompt research to define the expression and function of $\mathrm{IL}-12$ and $\mathrm{IL}-12$ receptor in NBS.

\section{REFERENCES}

1. Weemaes CM, Smeets DF, Van der Burgt CJ. Nijmegen breakage syndrome: a progress report. Int $J$ Radiat Biol. 1994;66:S185-S188.

2. Saar K, Chrzanowska KH, Stumm M, et al. The gene for the ataxiatelangiectasia variant, Nijmegen breakage syndrome maps to a $1-\mathrm{cM}$ interval on chromosome 8q21. Am J Hum Genet. 1997;60:605-610.

3. Varon R, Vissinga $C$, Platzer $M$, et al. Nibrin, a novel DNA double-strand break repair protein, is mutated in Nijmegen breakage syndrome. Cell. 1998;93:467-466.

4. Gregorek $\mathrm{H}$, Chrzanowska $\mathrm{KH}$, Michalkiewicz J, et al. Heterogeneity of humoral immune abnormalities in children with Nijmegen breakage syndrome: an 8-year follow-up study in a single centre. Clin Exp Imminol $2002 ; 130: 319-324$

5. Kumat B, Muralidhar S. Cutaneous tuberculosis: a twenty-year prospective study. Int J Tuberc Lung Dis. 1999;3:494-500.

6. Wozniacka A, Schwartz RA, Sysa-Jedrzejowska A, et al. Lupus vulgaris report of two cases. Int $J$ Dermatol. 2005:44:299-301.

7. Sehgal VN, Srivastava $G$, Bajaj $P$, et al. Reinfection (secondary) inoculation cutaneous tuberculosis. Int J Dermatol. 2001;40:205-209

8. Park $\mathrm{H}$, Jang $\mathrm{H}$, Kim $\mathrm{C}$, et al. Detection and identification of mycobacteria by amplification the internal transcribed spacer regions with genus- and species-specific PCR primers. J Clin Microbiol. 2000;38:4080-4085.

9. Woo PN, Batta $\mathrm{K}$, Tan CY, et al. Lupus vulgaris diagnosed after 87 years, presenting as an ulcerated birthmark. Br. I Dermatol. 2002;146:525-526.

10. Resnick IB, Kondratenko I, Togoev O, et al. Nijmegen breakage syndrome: clinical characteristics and mutation analysis in eight unrelated Russian families. J Pediatr. 2002; 140:355-361.

11. Maródi L, Notarangelo LD. Immunological and genetic bases of new primary imununodeficiencies. Nat Rev Immtmol. 2007;7:851-861.

12. Al-Muhsen S, Casanova JL. The genetic heterogeneity of mendelian susceptibility to mycobacterial disenses. $J$ Allorgy Clin Immunol. 2008;122. $1043-1051$

13. Dorman SE, Picard C, Lammas D, et al. Clinical features of dominant and recessive interferon gamma receptor 1 deficiencies. Lancet. 2004;364: $2113-2121$

14. Filipe-Santos O, Bustamante J, Chapgier A, et al. Inborn errors of IL-12/23and IFN-gammin-mediated immunity: molecular, cellular, and clinical features. Semin limmunol. 2006;18:347-361. 